\title{
VALORES HUMANOS NO DESIGN DE INTERAÇÃO: PROJETANDO TECNOLOGIAS INTERATIVAS PARA INCENTIVAR A RECICLAGEM
}

\section{HUMAN VALUES IN INTERACTION DESIGN: WORKING WITH INTERACTIVE TECHNOLOGIES TO ENCOURAGE RECYCLING}

\author{
Luciana Nunes ${ }^{1}$, M.Sc. \\ Claudia Mont'Alvão², D.Sc. \\ (1) PPG Design, Laboratório de Ergodesign e Usabilidade de Interfaces - LEUI PUC-Rio \\ e-mail: luciana.mn@gmail.com \\ (2) PPG Design, Laboratório de Ergodesign e Usabilidade de Interfaces - LEUI PUC-Rio \\ e-mail: cmontalvao@puc-rio.br
}

Valores Humanos, Design Colaborativo, Reciclagem

\begin{abstract}
O descarte incorreto de resíduos sólidos é um grande problema a ser enfrentado pelas nações. Projetar sistemas para a sustentabilidade significa lidar com o uso prolongado dos artefatos. É necessário considerar não apenas a usabilidade do artefato durante o uso, mas a experiência de uso como um todo, a qual envolve aspectos mais subjetivos. Dentre estes aspectos estão os valores humanos, que são tudo que consideramos importante na vida e que ajudam a construir significados. Assim, incorporá-los conscientemente nas fases iniciais do projeto é uma forma de possibilitar que os designers reflitam sobre eles, ajudando a construir soluções. Neste artigo, descrevemos a utilização de alguns valores numa atividade piloto de design colaborativo (workshop), tendo como foco a criação de um sistema de eco-feedback para informar e criar engajamento para a reciclagem. O resultado foi a elaboração de um fluxo de telas, no qual os designers documentaram os valores trabalhados.
\end{abstract}

\section{Human Values, Collaborative Design, Recycling}

The incorrect disposal of waste is a big problem facing nations. Designing systems for sustainability means to deal with the long-term use of an artifact. To stimulate this, it is necessary to consider not only the usability during the use but also the use experience as a whole, once it involves more subjective goals. Among these goals are human values, which are all we consider important in life and help to build meanings. Therefore, incorporate them consciously on the initial stages of the project is one way to allow designers' reflection over values, helping them to create solutions. In this paper, we describe the use of some values in a pilot activity of collaborative design (workshop), focusing on creating an eco-feedback system to inform and create engagement for recycling. The result was the elaboration of a screen flow, in which designers documented the values worked on. 


\section{$16^{\circ}$ \\ ERGODESIGN USIHC CINAHPA}

\section{Introdução}

Os avanços tecnológicos e sociais fizeram com que o Design se tornasse uma área estratégica, indo além da elaboração de produtos, estendendo-se também a serviços e sistemas, tanto físicos como digitais. A necessidade de se consumir aumentou consideravelmente e o Design contribuiu para isso. Contudo, o consumo exacerbado, aliado não só a rapidez da evolução tecnológica como também a outros fatores, acaba tendo consequências e uma delas é uma maior geração e descarte de resíduos.

O Design para a Sustentabilidade é um campo do Design com o objetivo de contribuir, através de pesquisas e da criação de artefatos para o desenvolvimento sustentável. Ele considera não apenas o ciclo de vida do produto, mas também o contexto de vida das pessoas que usufruirão dos produtos e/ou dos serviços, levando em conta seus valores pessoais. Diversas áreas se relacionam a ele, sendo uma delas a Ergonomia. Ela se entrelaça com a área de Design de Interação e, nesta interseção, encontra-se uma parte da área de Interação Humano-Computador. O Design de Interação envolve a elaboração de artefatos tecnológicos digitais para o uso das pessoas, considerando não apenas a usabilidade no momento do uso, mas também a experiência do usuário como um todo, envolvendo o momento anterior (antecipação ao uso) e posterior (reflexão pós-uso) ao uso do artefato (PADOVANI et al., 2012). Assim, considerando que sistemas computacionais são bens de consumo e estão cada vez mais presentes no dia-a-dia das pessoas, tornase importante a pesquisa voltada para a sustentabilidade dentro da área.

Ter a sustentabilidade como foco dos projetos de Design de Interação significa ter em mente não apenas o usuário direto do sistema, mas todos que, de certa forma, serão influenciados por ele. É também considerar o contexto no qual o projeto será inserido, aspectos econômicos, sociais e o próprio meio-ambiente. É pensar que o artefato desenvolvido deve utilizar menos recursos naturais e permitir um uso de longo prazo. É abordar como o design desses artefatos pode influenciar estilos de vida e tomadas de decisão em prol da $16^{\circ}$ Ergodesign - Congresso Internacional de Ergonomia e Usabilidade de Interfaces Humano Tecnológica: Produto, Informações Ambientes Construídos e Transporte

$16^{\circ}$ USIHC - Congresso Internacional de Ergonomia e Usabilidade de Interfaces Humano Computador

CINAHPA | 2017 - Congresso Internacional de Ambientes Hipermídia para Aprendizagem. sustentabilidade, incentivando a reflexão.

Para estimular o uso prolongado desses artefatos em dispositivos tecnológicos digitais computadores, celulares, tablets etc - é interessante envolver aspectos subjetivos referentes à experiência de uso que contribuem para o uso prazeroso e para o seu significado. Entre estes aspectos encontram-se os objetivos, as necessidades, as emoções e os valores humanos. Estes valores representam o que consideramos importante na vida e influenciam atitudes e intenções de ter comportamentos. Eles também ajudam na construção do significado, o qual, por sua vez, contribui para o uso prolongado de artefatos (SHEDROFF, 2009).

Neste artigo abordamos a incorporação dos valores humanos na etapa inicial do design de um sistema de eco-feedback voltado para informar e gerar engajamento a respeito da reciclagem. Eco-

feedback é uma tecnologia que tem como objetivo informar sobre comportamentos individuais ou coletivos com o objetivo de aumentar a conscientização e promover comportamentos ambientalmente responsáveis (FROEHLICH, 2011). Ele também é considerado uma estratégia de persuasão aplicada em tecnologias com foco na sustentabilidade. Para saber como isso ocorreria e até que ponto os designers conseguiriam trabalhar de maneira consciente com aspectos tão abstratos ligados à experiência do usuário, realizou-se uma atividade piloto de design colaborativo no formato de um workshop com 4 designers de interação e 1 participante não-designer, este último fazendo o papel de usuário do sistema, servindo de fonte consultiva para os designers. Entregou-se à equipe um briefing no qual se considerava 2 valores motivacionais pertencentes à Teoria de Valores Básicos (SCHWARTZ, 1992). Em seguida, realizou-se 3 atividades, as 2 primeiras utilizando a ferramenta Envisioning Cards (FRIEDMAN \& HANDRY, 2012), que ajuda a guiar o pensamento a respeito dos valores. Ao final das atividades, os participantes elaboraram um fluxograma de telas do sistema de eco-feedback baseado nos valores selecionados, apontando que sua incorporação de fato ajuda na reflexão da equipe de design.
Realização:

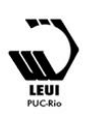




\section{$16^{\circ}$ \\ ERGODESIGN USIHC CINAHPA}

\section{Valores Humanos: da Psicologia para o Design de Interação}

Os valores humanos são estudados em diversas disciplinas, dentre as quais inclui-se a Psicologia, a Administração e o Design de Interação, este último especialmente através da abordagem Design Centrado no Usuário, que se concentra nas necessidades e objetivos dos usuários e seus comportamentos ao invés das funcionalidades dispostas nos sistemas (SAFFER, 2010). Pelo caráter comportamental, utilizou-se as definições e teorias sob a ótica da Psicologia, as quais influenciam diretamente o Design de Interação. Os valores envolvem aspectos emocionais e estão ligados às necessidades e objetivos, retratando um pequeno número de crenças. Crença é definida por SCHWARTZ (2012) como uma ideia sobre o quão verdadeiro é algo e pode ser mais ou menos intensa dependendo do grau de certeza que se tem em relação a esta veracidade. Estas crenças são armazenadas na memória através de processos cognitivos. Por causa de uma limitação da capacidade cognitiva das pessoas, apenas algumas são ativadas em momentos ou contextos específicos. Uma vez que um valor é internalizado, ele se torna, consciente ou inconscientemente, um padrão ou critério para guiar o comportamento e para desenvolver e manter as atitudes - positivas ou negativas - a respeito de pessoas, objetos e situações, bem como nossa propensão em aceitar ou rejeitar as regras ou padrões de comportamento (normas) impostos pela sociedade.

Os estudos dos valores dentro da Psicologia começaram com ROKEACH (1973) e serviram de base para que, posteriormente, SCHWARTZ (1992) elaborasse a Teoria de Valores Básicos. Um valor pode ser muito importante para alguém e irrelevante para outra pessoa e o que a teoria defende é que a diferença básica de um valor para o outro é a motivação para alcançar determinadas metas. A teoria de Schwartz é, desde então, amplamente utilizada, principalmente por seu caráter abrangente, podendo ser estudada tanto a nível individual como cultural. $16^{\circ}$ Ergodesign - Congresso Internacional de Ergonomia e Usabilidade de Interfaces Humano Tecnológica: Produto, Informações Ambientes Construídos e Transporte

$16^{\circ}$ USIHC - Congresso Internacional de Ergonomia e Usabilidade de Interfaces Humano Computador

CINAHPA | 2017 - Congresso Internacional de Ambientes Hipermídia para Aprendizagem.

\subsection{Os 10 valores motivacionais de Schwartz}

A Teoria de Valores Básicos possui 10 valores motivacionais, que são considerados universais por atenderem a requisitos humanos gerais: necessidades dos indivíduos como organismos biológicos, exigência de interação social coordenada e necessidade de sobrevivência e bemestar dos grupos. São eles:

\begin{tabular}{|c|c|c|}
\hline 1 & Autodeterminação & $\begin{array}{l}\text { Pensamento independente e ação - } \\
\text { escolher, criar, explorar. Está } \\
\text { relacionado às necessidades biológicas } \\
\text { de controle e domínio e às exigências } \\
\text { de interação necessárias à autonomia e } \\
\text { à independência. }\end{array}$ \\
\hline 2 & Benevolência & $\begin{array}{l}\text { Preservação e aumento do bem-estar } \\
\text { das pessoas com as quais mantém-se } \\
\text { contato pessoal frequente. Os valores } \\
\text { ligados à benevolência vêm da } \\
\text { necessidade de harmonia em um grupo } \\
\text { e da necessidade de filiação de um } \\
\text { indivíduo, enquanto organismo } \\
\text { biológico. }\end{array}$ \\
\hline 3 & Conformidade & $\begin{array}{l}\text { Restrição de ações, inclinação e } \\
\text { impulsos suscetíveis a perturbação ou } \\
\text { danos a outras pessoas, além de } \\
\text { violação de expectativas ou de normas } \\
\text { sociais. Estes valores vêm da } \\
\text { necessidade dos indivíduos de } \\
\text { controlarem seus desejos e ações que } \\
\text { poderiam impactar no bom } \\
\text { funcionamento de interações com o } \\
\text { grupo. }\end{array}$ \\
\hline 4 & Estimulação & $\begin{array}{l}\text { Excitação, novidade e desafios na vida. } \\
\text { Os valores ligados à estimulação se } \\
\text { originam da necessidade biológica de } \\
\text { variedade e estimulação a fim de } \\
\text { manter um nível ideal e positivo de } \\
\text { atividades. }\end{array}$ \\
\hline 5 & Hedonismo & $\begin{array}{l}\text { Prazer e satisfação a si próprio. Provêm } \\
\text { da necessidade humana de sentir prazer } \\
\text { associado à satisfação. }\end{array}$ \\
\hline 6 & Poder & $\begin{array}{l}\text { Status social e prestígio, controle ou } \\
\text { domínio sobre pessoas, tanto a nível } \\
\text { individual como intrapessoal, e } \\
\text { recursos em um sistema social. }\end{array}$ \\
\hline 7 & Realização & $\begin{array}{l}\text { Sucesso pessoal através da } \\
\text { demonstração de competências de } \\
\text { acordo com as normas sociais. Está } \\
\text { vinculado à necessidade de gerar } \\
\text { recursos necessários para a } \\
\text { sobrevivência do indivíduo e para o }\end{array}$ \\
\hline
\end{tabular}

Realização:
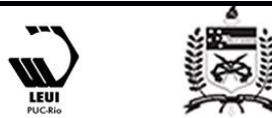


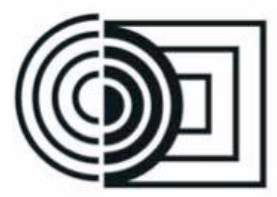

$16^{\circ}$ Ergodesign - Congresso Internacional de Ergonomia e Usabilidade de Interfaces Humano Tecnológica: Produto, Informações Ambientes Construídos e Transporte

$16^{\circ}$ USIHC - Congresso Internacional de Ergonomia e Usabilidade de Interfaces Humano Computador

CINAHPA | 2017 - Congresso Internacional de Ambientes Hipermídia para Aprendizagem.

\begin{tabular}{|c|c|l|}
\hline & & $\begin{array}{l}\text { alcance de objetivos do grupo e de } \\
\text { instituições. }\end{array}$ \\
\hline 8 & Segurança & $\begin{array}{l}\text { Segurança, harmonia e estabilidade da } \\
\text { sociedade, dos relacionamentos e do } \\
\text { indivíduo. Provém das necessidades } \\
\text { básicas, tanto a nível individual como } \\
\text { em grupo de ordem e segurança. }\end{array}$ \\
\hline 9 & Tradição & $\begin{array}{l}\text { Respeito, comprometimento e } \\
\text { aceitação dos costumes e ideias que a } \\
\text { cultura tradicional ou religião promove } \\
\text { ao indivíduo. Contribui para a } \\
\text { sobrevivência e unidade do grupo. }\end{array}$ \\
\hline 10 & Universalismo & $\begin{array}{l}\text { Compreensão, apreciação, tolerância e } \\
\text { proteção pelo bem-estar das pessoas e } \\
\text { pela natureza. Vêm da necessidade de } \\
\text { sobrevivência do indivíduo e de grupos } \\
\text { e são ligados tanto ao ser humano } \\
\text { como à natureza. }\end{array}$ \\
\hline
\end{tabular}

Tabela 1 - Os 10 valores motivacionais. Fonte: SCHWARTZ, 1992 (tradução nossa).

Cada valor motivacional possui uma série de valores associados a ele, como por exemplo, criatividade (autodeterminação), amizade verdadeira (benevolência), obediência (conformidade) e assim por diante. Estes valores se relacionam de forma dinâmica, podendo ser priorizados pelos indivíduos. As consequências práticas, psicológicas ou sociais podem ser conflitantes ou congruentes. Para ilustrar tal dinâmica, o autor propôs o modelo circular abaixo:

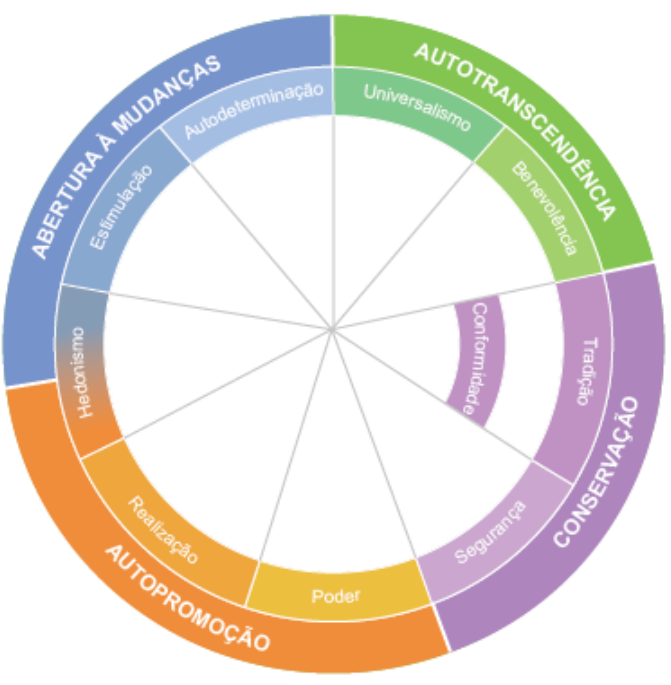

Figura 1 - Modelo circular dos valores motivacionais com os 2 eixos ortogonais. Fonte: SCHWARTZ, 1992 (tradução nossa).
É possível manipular através de experimentos a priorização de um valor, o que mostra que eles podem mudar não apenas ao longo da vida como até mesmo no dia-a-dia. Quando um valor é priorizado, os valores opostos a ele no modelo circular tendem a ser suprimidos e os congruentes tendem a ser ativados (HOLMES et al., 2011; KNOWLES et al., 2014).

Observa-se na figura que os valores foram organizados em 4 eixos maiores: Abertura à mudança (independência e prontidão para a mudança) x Conservação (Auto restrição, preservação do passado e resistência a mudanças) e Autotranscendência (preocupação com o bem-estar dos outros) x Autopromoção (busca pelo status social e sucesso). Estudos mostram que os valores também podem ser associados a comportamentos pró-ambientais (KARP, 1996; STERN, 2000; PATO \& TAMAYO, 2006), especialmente os que fazem parte do eixo Autotranscendência e Abertura à mudança, possuindo forte influência positiva.

\subsection{Os valores na IHC: abordagem Value- Sensitive Design}

Os valores também são estudados dentro da IHC e possuem diversas abordagens. Uma delas é a Value-Sensitive Design (FRIEDMAN et al., 2006), a qual defende a incorporação dos valores durante o processo de design. Como eles influenciam as diversas fases do projeto, a Value-Sensitive Design prega que é necessário explicitá-los, assim como as tensões existentes entre eles e as trocas de valores que podem ocorrer durante o processo ou até mesmo após o uso. É, portanto, um processo iterativo, dividido em 3 etapas de investigação: conceitual, empírica e técnica. A investigação conceitual analisa as questões e construções centrais em relação ao projeto, como por exemplo quem são os stakeholders diretamente $\mathrm{e}$ indiretamente afetados pelo uso da tecnologia e como um valor é ressaltado ou diminuído por uma tecnologia. A diferença entre stakeholders diretos e indiretos é que os primeiros são as pessoas que de fato interagem com o sistema, enquanto os indiretos são aqueles que também são impactados pelo sistema, mesmo não tendo interagido diretamente com ele. A investigação empírica visa,
Realização:
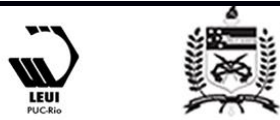


\section{$16^{\circ}$ \\ ERGODESIGN USIHC CINAHPA}

$16^{\circ}$ Ergodesign - Congresso Internacional de Ergonomia e Usabilidade de Interfaces Humano Tecnológica: Produto, Informações Ambientes Construídos e Transporte

$16^{\circ}$ USIHC - Congresso Internacional de Ergonomia e Usabilidade de Interfaces Humano Computador

CINAHPA | 2017 - Congresso Internacional de Ambientes Hipermídia para Aprendizagem. através da coleta de dados, entender os contextos, o entendimento e a experiência de pessoas que são afetadas pelo artefato tecnológico. Já a

investigação técnica trata de como os mecanismos existentes em uma tecnologia ressaltam ou escondem os valores identificados na investigação conceitual. A diferença entre a investigação empírica e a técnica é que a primeira foca no indivíduo, grupo ou sistemas sociais maiores que configuram, utilizam ou são afetados pelo artefato tecnológico. Já a segunda foca na tecnologia propriamente dita.

Para auxiliar os designers e desenvolvedores em projetos que visam não apenas os valores como também o uso prolongado do artefato, foi desenvolvido um conjunto de ferramentas em formato de cartões denominado Envisioning Cards (NATHAN et al., 2009; FRIEDMAN \& HANDRY, 2012). Os cartões foram divididos em 4 critérios considerados importantes para projetos de longo prazo: stakeholders, tempo, valores e ubiquidade. Cada cartão apresenta um tema, uma atividade sugerida relacionada ao tema, o critério ao qual pertence e uma imagem para ilustrar o tema descrito. Cabe a equipe de projeto escolher em que etapa do projeto utilizará os cartões, quanto tempo despenderá neles, quais cartões serão usados e como será esse uso.

O que ocorre é que ao interagirmos com um artefato tecnológico carregamos nossos próprios valores. Mesmo que este artefato tenha valores incorporados a ele que foram intencionados pela equipe (designers, desenvolvedores, gerentes etc), os valores pessoais do usuário exercem influência no valor que é percebido durante e após o uso do artefato. Por essa razão, é importante conhecer os valores dos usuários e, a partir deles, incorporar valores na tecnologia que satisfaçam seus objetivos e necessidades.

Embora a Value-Sensitive Design se concentre em valores considerados éticos e sugira uma lista de possíveis valores a serem trabalhados, FRIEDMAN et al. (2006) ressaltam que ela não tem pretensão de ser definitiva, permitindo a utilização de outros valores que não constem nela. Isso possibilita a utilização dos valores de
Schwartz na abordagem Value-Sensitive Design: primeiro, por serem universais; segundo, por ter sido testado em vários países e culturas, incluindo o Brasil.

\section{Workshop: a incorporação dos valores no design de um sistema de eco-feedback para a reciclagem}

Tendo como base a teoria apresentada anteriormente, resolveu-se trabalhar os valores associados à reciclagem. Estas informações foram levantadas em uma fase anterior, referente à etapa conceitual da Value-Sensitive Design, através da aplicação de questionários com moradores maiores de 18 anos da cidade do Rio de Janeiro, considerados stakeholders diretos e indiretos da tecnologia. Após analisar os valores priorizados que mais se correlacionavam com comportamentos ligados à reciclagem, decidiu-se trabalhar os valores motivacionais Universalismo e Autodeterminação, pertencentes, respectivamente, aos eixos Autotranscendência e Abertura a mudança na etapa empírica da abordagem. Esta etapa envolveu um design colaborativo através de uma atividade piloto no formato de workshop e os valores selecionados fizeram parte do briefing entregue à equipe de design.

\subsection{Organização do workshop}

A ideia do design colaborativo é permitir que o time crie conceitos de produtos juntos, ajudando-os a alcançar um entendimento coletivo sobre o problema e a solução de design (GOTHELF, 2013). O objetivo do workshop foi estimular os participantes a pensar sobre os valores humanos e inserí-los no design de tecnologias a fim de contribuir para uma boa experiência de uso. A ênfase foi em tecnologias voltadas para incentivar a reciclagem. Os participantes foram convidados a:

- Refletir sobre quais valores consideram importantes para existir na tecnologia a ser trabalhada;
Realização:

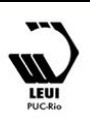




\section{$16^{\circ}$ \\ ERGODESIGN USIHC CINAHPA}

$16^{\circ}$ Ergodesign - Congresso Internacional de Ergonomia e Usabilidade de Interfaces Humano Tecnológica: Produto, Informações Ambientes Construídos e Transporte

$16^{\circ}$ USIHC - Congresso Internacional de Ergonomia e Usabilidade de Interfaces Humano Computador

CINAHPA | 2017 - Congresso Internacional de Ambientes Hipermídia para Aprendizagem.
- Levantar as possíveis tensões que a escolha de um ou outro valor pudesse acarretar na tecnologia;

- Gerar ideias de como representar estes valores na tecnologia (objetos de interface e funcionalidades), considerando o objetivo da mesma;

- Rascunhar a ideia escolhida.

Para simular um time pequeno, recrutou-se 4 designers de interação com diferentes níveis de experiência, todos atuando na área de design de interface e interação: P1 e P2 eram formados com habilitação em design de produto, $\mathrm{P} 3 \mathrm{em}$ design gráfico e P4 com ambas habilitações. Todos os participantes possuíam especialização lato sensu completa, 3 em Ergodesign de Interfaces (P2, P3 e P4) e 1 em Marketing Digital (P1). Um dos participantes (P4) estava cursando mestrado em Design. Além dos designers, recrutou-se também 1 participante (P5) que era de outra área (pertencia à área de saúde), representando os cidadãos comuns. A ideia foi que este participante fizesse o papel de usuário do sistema, servindo de fonte consultiva para a equipe de design. O pré-requisito para a escolha desse usuário foi ter uma experiência de uso de dispositivos tecnológicos digitais (ao menos computadores e celulares) de moderada a alta. Os participantes foram contatados pela pesquisadora pessoalmente e por mensagem de texto. Todos compareceram ao evento e a sessão foi filmada, para auxiliar a pesquisadora posteriormente, $\mathrm{e}$ fotografada, para ilustrar o processo.

O workshop foi estruturado da seguinte maneira: primeiro, os participantes assinavam um termo de consentimento da pesquisa. Em seguida, apresentava-se alguns conceitos-chave, como os valores humanos, tecnologias persuasivas e o ecofeedback, para facilitar o entendimento em relação ao que seria trabalhado. Terminada a apresentação, iniciavam-se as atividades, que foram divididas em 3 fases: (1) Visões de cada integrante e seleção de 1 opção; (2) Seleção da ideia e decisão conjunta; e (3) Rascunhos do protótipo no papel. A primeira fase, individual, era composta de 3 atividades, as 2 primeiras referentes aos seguintes cartões da ferramenta Envisioning Cards: "Choose Desired Values" e "Values Tensions". Estes cartões não foram mostrados diretamente aos participantes: serviram para que a pesquisadora selecionasse as atividades a serem passadas aos participantes. Já a segunda e terceira fase eram em grupo. A duração total planejada para o workshop era de 5 horas.

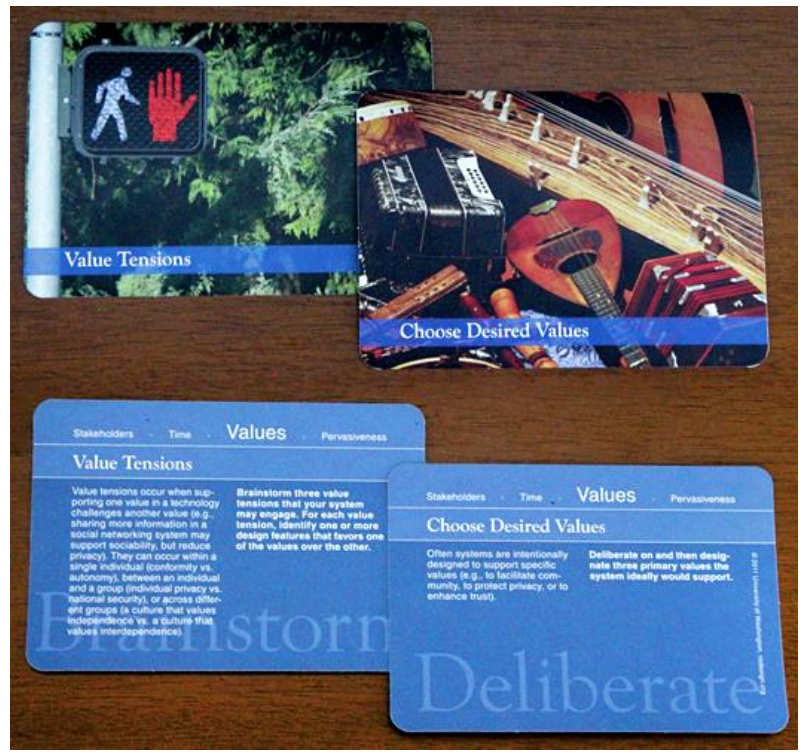

Figura 2 - Cartões da ferramenta Envisioning Cards utilizados. Fonte: FRIEDMAN \& HANDRY, 2012.

A expectativa para este workshop era que os designers chegassem a algum rascunho inicial do sistema de eco-feedback, materializando os valores escolhidos em objetos de interface e funcionalidades. Acreditava-se que por sugerir um enfoque em aspectos bastante subjetivos eles, mesmo sendo profissionais com expertises e experiência profissional na área, sentissem mais dificuldade na terceira atividade da primeira fase, que era a materialização dos valores escolhidos em objetos de interface. Esperava-se que o fato desta primeira fase ser individual fizesse com que mais ideias fossem geradas. As atividades da segunda e terceira fase seriam menos críticas e facilitariam o processo, pois eram em grupo. Acreditava-se também que o dispositivo escolhido para comportar o sistema de eco-feedback fosse o celular, por ser um dispositivo comum entre a maioria das pessoas e pela sua mobilidade.

\subsection{Equipe de design em ação: projetando a partir de valores humanos}

Realização:
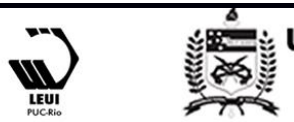


\section{$16^{\circ}$ \\ ERGODESIGN USIHC CINAHPA}

Após assinarem o termo de consentimento e de serem apresentados brevemente à teoria que envolvia o trabalho, os participantes receberam o briefing do projeto, que era composto de 6 itens: demanda, produto, comportamento-alvo, tipo de mudança, público-alvo, dificuldades para o comportamento e pré-requisitos. Além do briefing, foi mostrado também aos participantes 4 personas, representantes do público-alvo. Vale ressaltar que todas as informações contidas no briefing e que originaram as personas foram levantadas na etapa conceitual, a partir de revisão de literatura, de entrevistas semiestruturadas com stakeholders, e dos questionários para identificar os valores, já mencionados anteriormente.

A demanda foi projetar uma tecnologia interativa digital para incentivar a reciclagem e o produto um sistema de eco-feedback. O comportamento-alvo a ser trabalhado, no caso a separação em casa de frascos plásticos feitos de PET, era um recorte de um comportamento maior, que era incentivar a reciclagem. Esse comportamento maior é composto de uma série de outros comportamentos que estão interligados. Dessa forma, a separação dos materiais PET em casa poderia estar associada, por exemplo, a outros 2 comportamentos, que eram colocar o material em algum recipiente e ter acesso a algum serviço de coleta. Considerando o contexto abordado, explicou-se que o foco era na separação, mas que se os participantes sentissem necessidade de tratar estes 2 comportamentos associados, não seriam impedidos. O tipo de mudança desejada era na atitude (avaliações, positivas ou negativas) dos usuários sobre a intenção (motivação) em ter o comportamento-alvo e o público-alvo os moradores da cidade do Rio de Janeiro. As dificuldades listadas para o comportamento foram 3: (1) O fato dos indivíduos não perceberem os benefícios de reciclar, que era ligado à motivação; (2) Falta de tempo e (3) falta de hábito/ esquecimento, ambos ligados à habilidade. Os objetivos eram criar atenção para a situação em questão e engajá-las. Como prérequisitos, mostravam-se os valores humanos a serem trabalhados, algumas estratégias de persuasão pré-definidas e aspectos da interação com a informação, como frequência de atualização das informações, o esforço que os usuários $16^{\circ}$ Ergodesign - Congresso Internacional de Ergonomia e Usabilidade de Interfaces Humano Tecnológica: Produto, Informações Ambientes Construídos e Transporte

$16^{\circ}$ USIHC - Congresso Internacional de Ergonomia e Usabilidade de Interfaces Humano Computador

CINAHPA | 2017 - Congresso Internacional de Ambientes Hipermídia para Aprendizagem.

deveriam despender para acessar o conteúdo, a quantidade de atenção necessária para visualizá-la e a granularidade dos dados e da informação.

\begin{tabular}{|ll|}
\hline AUTOTRANSCENDÊNCIA & ABERTURA À MUDANÇA \\
\hline Universalismo & Autodeterminaçăo \\
\hline Mente aberta & Criatividade \\
\hline Justiça social & Liberdade \\
\hline Igualdade & Escolha das próprias metas \\
\hline Mundo de paz & Curioso(a) \\
\hline Mundo de belezas & Independente \\
\hline Unidade com a natureza & Respeito por si próprio* \\
\hline Sabedoria & Inteligente* \\
\hline Proteger o meio-ambiente & Privacidade $^{*}$ \\
\hline Harmonia interna & \\
\hline Vida espirituosa & \\
\hline
\end{tabular}

Figura 3 - Lista dos valores motivacionais presentes no briefing com seus valores associados. Fonte: baseado em SCHWARTZ (1992) e PATO-OLIVEIRA E TAMAYO (2002).

Na primeira fase, Visões de cada integrante e seleção de 1 opção, a primeira atividade apresentada era baseada no cartão Choose Desired Values. Os participantes deveriam escolher 3 valores em ordem de preferência para cada grupo que, na visão deles e considerando o briefing, acham que o sistema de eco-feedback deveria comportar. O valor "proteger o meio-ambiente", associado ao tipo motivacional Universalismo, vinha como um pré-requisito do sistema, cabendo aos participantes escolher outros valores deste grupo.

Em seguida, apresentou-se a segunda atividade, baseada no cartão Value Tensions, na qual uma vez escolhido os 3 valores priorizados, cada participante deveria pensar em até 3 tensões que cada um desses valores poderia causar. Quando se diz tensão é pela própria natureza dos valores que, ao se priorizar um, diminui-se outro (chamado de efeito gangorra). Essas tensões acabavam funcionando como entraves para se alcançar o valor desejado. Para cada tensão detectada, o participante deveria pensar em funcionalidades que as representassem. O P5 deveria levantar os 3 valores mais prioritários e as possíveis tensões que existissem da escolha desses valores, mas não 


\section{$16^{\circ}$ \\ ERGODESIGN USIHC CINAHPA}

precisaria pensar nas funcionalidades, cabendo a ele apenas auxiliar os designers.

Embora a ideia fosse que os participantes realizassem as tarefas 1 e 2 de maneira contínua, eles preferiram fazer uma de cada vez sob o argumento que era muita informação e se sentiam mais confortáveis dessa maneira. Deu-se 5 minutos para que os participantes escolhessem os valores. Durante esta etapa observou-se que alguns participantes tiveram dificuldades em entender o que os valores da lista proposta por SCHWARTZ (1992) significavam, como P1, que disse estar tendo dificuldades e não saber o que significava o valor harmonia interna, mas de uma maneira geral essa etapa foi concluída de maneira satisfatória.

Já a segunda tarefa, referente às tensões e funcionalidades, apresentou algumas dificuldades. A proposta era que cada participante pensasse individualmente sobre elas, fazendo com que não apenas refletissem sobre os valores, mas que visualizassem funções que poderiam ressaltar essas tensões. Logo, essas funcionalidades deveriam ser evitadas ou repensadas. Um dos participantes chegou a questionar se não seria melhor fazer isso em grupo, mas os demais acharam que o fato de ser individual os faria refletir melhor sobre as tensões. Os participantes tiveram 30 minutos para completarem a tarefa. As tensões foram levantadas de forma individual, porém os participantes acabaram trocando algumas ideias sobre elas. $\mathrm{O}$ grande problema foram as funcionalidades. Os participantes entenderam que elas seriam para corrigir as funções, ou seja, soluções, quando na verdade elas deveriam representar justamente as tensões levantadas. Isso causou um ruído no fluxo da tarefa, fazendo com que os participantes ficassem travados em lidar com aspectos tão subjetivos antes de pensar no dispositivo.

"Eu não sei se consigo pensar em funcionalidades pra todas as tensões que coloquei porque são tensões que coloquei de forma abstrata, que tem a ver com valores e não com materialização" (Participante P4).

Para resolver o impasse das funcionalidades, os participantes acharam melhor, a partir dos valores priorizados por cada um, das tensões detectadas, do briefing e das personas, discutir e chegar num $16^{\circ}$ Ergodesign - Congresso Internacional de Ergonomia e Usabilidade de Interfaces Humano Tecnológica: Produto, Informações Ambientes Construídos e Transporte

$16^{\circ}$ USIHC - Congresso Internacional de Ergonomia e Usabilidade de Interfaces Humano Computador

CINAHPA | 2017 - Congresso Internacional de Ambientes Hipermídia para Aprendizagem. consenso sobre os valores a serem trabalhados neste momento ao invés de trabalharem individualmente e gerarem mais soluções. Além disso, acharam mais fácil ver as funcionalidades como solução das tensões do que como representantes delas. A equipe deveria escolher 3 valores para representar o Universalismo e a Autodeterminação. Assim, os valores escolhidos foram criatividade, escolha das próprias metas (ambas representantes da Autodeterminação) e unidade com a natureza, além do valor já prédefinido, proteger a natureza (Universalismo).

“A primeira intenção é fazer com que a pessoa utilize o que a gente vai criar, né? Então, a gente tem que usar a criatividade pra que ela utilize. A gente acredita que ela tendo autonomia pra escolher as próprias metas ela vai se motivar a continuar utilizando; e a unidade com a natureza é na verdade o objetivo geral e final, que é fazer com que a pessoa se sinta parte de uma coisa maior e que ela passe a ter empatia por essa causa" (Participante P1).

Como os participantes acabaram subvertendo algumas etapas e por terem achado difícil pensar em funcionalidades para as tensões sem saber qual dispositivo iriam utilizar, a última tarefa desta fase não foi realizada. Iniciou-se, então, a segunda fase, Seleção da ideia e decisão conjunta. Aqui os participantes deveriam realizar 2 tarefas: A primeira foi pensar no dispositivo a ser usado para o eco-feedback. No início, cogitou-se o celular, por ser um dispositivo mais difundido entre as pessoas, o que faria com que tivessem um alcance maior de público (P1 e P4). Outros participantes (P2 e P3) argumentaram se não poderia ser um objeto (ex: lixeira) interativo e digital, com o sistema acoplado. Os designers foram lembrando de alguns exemplos, como aplicativos voltados para atividades físicas, para estimular as pessoas a beberem mais água e para controle de energia. P5, no entanto, ressaltou que aplicativos como os de atividade física interferem diretamente no indivíduo, enquanto um de reciclagem não e por isso, para usá-lo, teria que ter uma motivação forte. Por fim, chegaram à conclusão que apenas 1 dispositivo não seria suficiente para atender aos requisitos do briefing e optaram por trabalhar o sistema de eco-feedback em 2 dispositivos: um totem interativo com um compartimento acoplado
Realização:
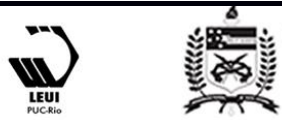


\section{$16^{\circ}$ \\ ERGODESIGN USIHC CINAHPA}

e um celular, nos quais os canais de interação seriam um software para o primeiro e um aplicativo para o segundo. O totem, onde você poderia depositar o PET, faria o papel de conscientização para o usuário realizar a separação em casa e deveria ser colocado em locais com grande circulação de pessoas, como pontos de ônibus, shoppings ou metrô. Já o aplicativo estaria relacionado a metas e ajudaria o indivíduo a se monitorar.

"Eu acho que seria legal pensar num totem justamente pensando na questão coletiva. Como a gente acha que as pessoas individualmente não fossem motivadas, ter isso em um lugar público e ver outras pessoas interagindo talvez aproxime mais as pessoas de usarem. A pessoa tá passando e talvez instigue a curiosidade. (...) são 2 coisas diferentes: o totem é uma informação mais coletiva e o aplicativo é mais pessoal" (Participante P1).

Definidos os dispositivos e canais, a segunda tarefa era saber qual papel o sistema faria para o usuário, baseado na tríade funcional de FOGG (2003), e escolher algumas estratégias ligadas a eles. Este material foi apresentado como conceito-chave da pesquisa, antes de iniciar as atividades. Os participantes entenderam que o sistema exerceria um papel de ferramenta, isto é, de auxiliar o usuário a atingir um comportamento-alvo, e de meio, referente ao uso de simulações para promover a experiência. As estratégias associadas a estes 2 papéis que foram escolhidas foram auto monitoramento e simulação em contextos do mundo real.

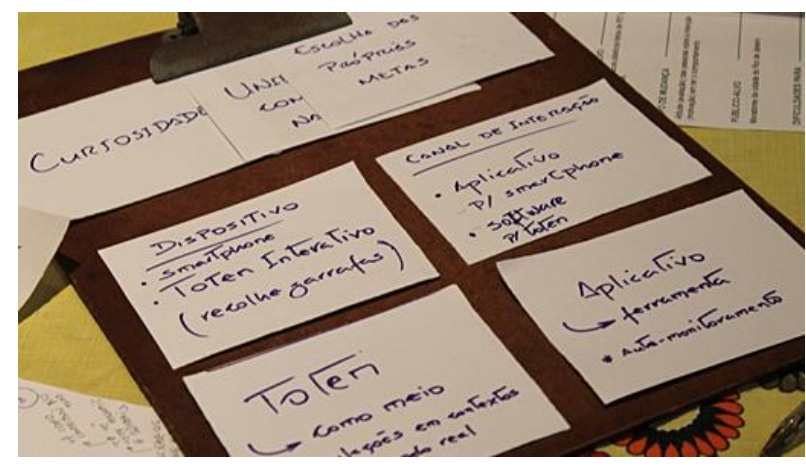

Figura 4 - Dispositivos, canais e estratégias para o ecofeedback selecionados. Fonte: elaboração própria, 2017. $16^{\circ}$ Ergodesign - Congresso Internacional de Ergonomia e Usabilidade de Interfaces Humano Tecnológica: Produto, Informações Ambientes Construídos e Transporte

$16^{\circ}$ USIHC - Congresso Internacional de Ergonomia e Usabilidade de Interfaces Humano Computador

CINAHPA | 2017 - Congresso Internacional de Ambientes Hipermídia para Aprendizagem.

A terceira e última fase era rascunhar a ideia no papel, a fim de chegar em um protótipo inicial. Nesta fase o P5 não esteve presente pois precisou sair, restando apenas os 4 designers. Antes de começarem a desenhar, a pesquisadora entregou uma folha contendo as expectativas de design para o sistema, baseados em alguns aspectos do design de eco-feedback propostos por FROEHLICH (2011). Os designers deveriam considerar questões como quem entraria com os dados no sistema (o próprio usuário ou seria automático?), como os dados seriam representados (a aparência deveria ser mais concreta e direta ou mais abstrata e indireta?), quem definiria as metas (o próprio usuário, o sistema ou outras entidades?), dentre outros. Após preencherem as expectativas de design, os participantes começaram a rascunhar a ideia do sistema. Como eles escolheram 2 dispositivos e o tempo restante do workshop era curto para produzir os 2 , orientou-se trabalhar apenas 1 dos dispositivos. A equipe escolheu focar na interação com o totem. O resultado dessa atividade foi o fluxo das telas (Figura 5).

No final, foi solicitado à equipe como um todo as impressões de se utilizar esta abordagem de valores humanos na fase de ideação do projeto. A visão do grupo foi que os valores ajudaram a pensar em outros aspectos que inicialmente não seriam contemplados. Porém, para eles o principal não foi a escolha dos valores, mas sim o debate que surgiu a partir do momento que se viram obrigados a pensar sobre eles. Isso fez com que questões emergissem, como a coletividade.

“(...) uma coisa que acho que mudou totalmente o que eu tava pensando, que a gente definiu no final foi a questão do coletivo, de tentar um produto que atendesse coletivamente e antes da gente discutir valores eu tava muito "pá, smartphone"” (Participante P1).

Apesar disso, os participantes fizeram algumas críticas também. Primeiro, eles acharam que as tensões foram pouco discutidas. Focou-se muito na discussão dos valores, mas não da tensão que poderia ocorrer ao se priorizar um determinado valor. O que ocorreu é que, somente após a escolha
Realização:
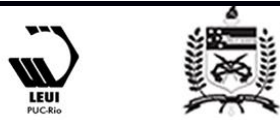
$16^{\circ}$ USIHC - Congresso Internacional de Ergonomia e Usabilidade de Interfaces Humano Computador

CINAHPA | 2017 - Congresso Internacional de Ambientes Hipermídia para Aprendizagem.

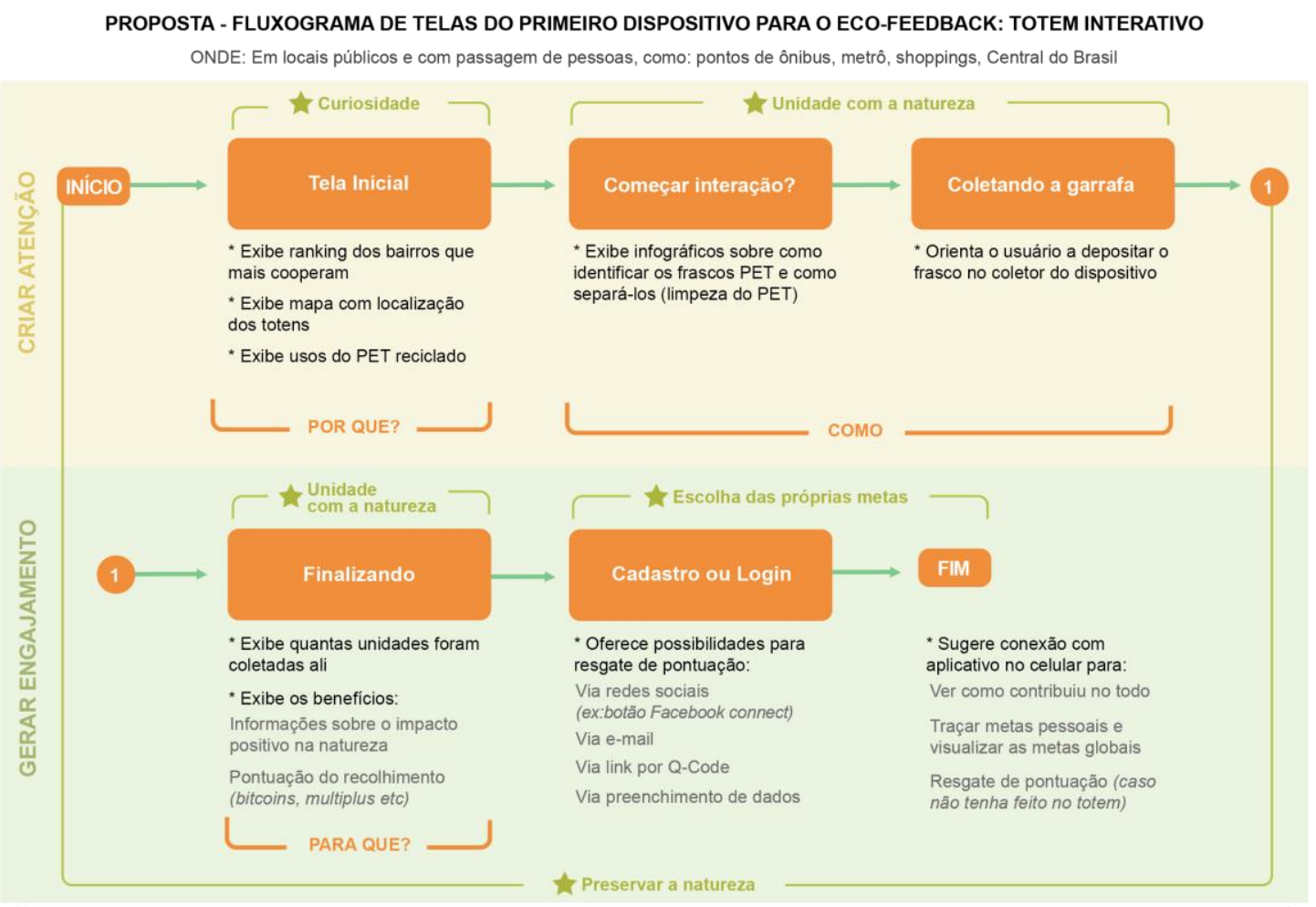

Figura 5 - Fluxograma de telas do totem para o sistema de eco-feedback. Fonte: elaboração própria, 2017.

do dispositivo, começou-se a pensar em algumas restrições, mas que não necessariamente tinham a ver com as tensões sugerida. Segundo, eles questionaram se o papel assumido pelos valores não poderia ser determinado por outra coisa, como objetivos e necessidades, que, de acordo com o entendimento deles, compõem a visão do produto. Por fim, acharam que as personas poderiam ter sido melhor aproveitadas e que todas, apesar de suas diferenças, representavam em sua a maioria indivíduos de classe média.

\section{Conclusão e desdobramentos}

A realização do workshop permitiu levantar algumas questões, positivas e negativas, a respeito do uso dos valores para guiar a fase inicial do projeto de eco-feedback. Primeiro, notou-se que a reflexão sobre os valores não é algo muito trivial, mas é possível. Na verdade, esse processo já ocorria entre os designers, mas de maneira implícita: estamos mais acostumados no dia-a-dia, tanto no âmbito profissional como acadêmico, a lidar com termos como objetivos e necessidades que, de certa forma, fazem parte de maneira consciente do trabalho do designer, deixando-o numa espécie de zona de conforto. Atender os objetivos e necessidades é contribuir para que o projeto a ser desenvolvido, seja um serviço ou produto, tenha um significado para o seu usuário.

Quando o designer é convidado a pensar nos valores humanos, estamos lidando com um outro nível em direção ao significado, mais profundo, inconsciente e abstrato, o que acaba, de certa maneira, tirando-o da zona de conforto. O que a atividade mostrou é que o ato de pensar em valores humanos causou à primeira vista um desconforto, mas que no decorrer da atividade foi bastante interessante para ajudar a vislumbrar algumas questões que poderiam não emergir naquele momento.

Tamanha abstração também trouxe dificuldades que não haviam sido esperadas. A principal questão foi em relação à listagem das funcionalidades referentes às tensões detectadas entre valores. Esta foi uma atividade proposta pela ferramenta Envisioning Cards que neste momento 


\section{$16^{\circ}$ \\ ERGODESIGN USIHC CINAHPA}

não funcionou exatamente como o esperado e causou muitas dúvidas nos participantes, fazendoos exceder muito o tempo proposto, comprometendo o andamento do restante da atividade. Em parte, isso pode ter ocorrido pelo fato de se ter incluído esta atividade em um momento individual, onde os participantes ainda estavam se familiarizando com os valores e as tensões. Isso fez com que eles não conseguissem pensar a priori nas funcionalidades que causavam as tensões levantadas e nem materializar do jeito esperado os objetos de interface a serem desenhados. A terceira atividade da primeira fase não foi concluída. Dessa forma, acredita-se que possa ser interessante trazer aos participantes exemplos de funcionalidades que possam causar algumas tensões, para não ficar tão abstrato.

Outro ponto foi com relação à escolha dos valores: determinou-se como pré-requisito o valor "proteger o meio-ambiente", associado ao Universalismo, por entender que se tratando de um sistema que visa incentivar a reciclagem, a questão ambiental estaria implícita. O objetivo era que os participantes considerassem outros valores ligados ao Universalismo e que não necessariamente estão diretamente ligados a questões ambientais, como justiça social, igualdade ou mente aberta. KNOWLES et al. (2014) dizem na sua estratégia "promover a autotranscendência" que tais valores citados também poderiam motivar comportamentos pró-ambientais. O que ocorre é que além do valor proteger o meio-ambiente, outros 2 valores também remetiam à natureza (unidade com a natureza e mundo de belezas) não foram percebidos como pré-requisitos pela pesquisadora Isso fez com que a esfera ambiental se mostrasse, novamente, com mais presença no sistema em relação às esferas econômica e social, especialmente na questão dos benefícios, usados como um dos fatores para o engajamento. Apesar disso, pela solução proposta, percebe-se que houveram também preocupações econômicas e sociais em relação ao uso do sistema, em parte ajudadas pela reflexão dos valores escolhidos.

Apesar das dificuldades, questões interessantes surpreenderam, como o fato de decidirem por um totem em locais públicos, e não apenas o celular. $16^{\circ}$ Ergodesign - Congresso Internacional de Ergonomia e Usabilidade de Interfaces Humano Tecnológica: Produto, Informações Ambientes Construídos e Transporte

$16^{\circ}$ USIHC - Congresso Internacional de Ergonomia e Usabilidade de Interfaces Humano Computador

CINAHPA | 2017 - Congresso Internacional de Ambientes Hipermídia para Aprendizagem.

Durante a escolha do dispositivo, questões como coletividade e inclusão de uma maior quantidade possível de usuários entraram em discussão, emergidas a partir da reflexão sobre os valores, conforme mencionado pelos próprios integrantes. Os participantes chegaram ao final da dinâmica com um fluxograma de telas referente ao sistema de eco-feedback e sinalizaram quais valores seriam trabalhados e quais possíveis soluções, chegando a sugerir por escrito alguns objetos de interface e funcionalidades no momento em que estavam elaborando o fluxograma.

A incorporação dos valores em etapas iniciais do design mostrou-se positiva, especialmente em temas ligados à sustentabilidade, a exemplo da reciclagem. Como próximos passos, é interessante dar continuidade à solução proposta pela equipe desta pesquisa, chegando a um protótipo de altafidelidade. Sugere-se também que estudos futuros possam melhorar o tempo da dinâmica como um todo e a escolha das atividades aplicadas, a fim de tentar ilustrar os valores em objetos de interface, e aplicar a dinâmica com outros grupos de designers de diferentes níveis de experiência e de instrução para verificar como se comportam ao lidar com os valores.

\section{BIBLIOGRAFIA}

FOGG, B. J. Persuasive Technology: Using Computers to Change What We think and do. San Francisco: Morgan Kaufmann, 2003. 283p.

FRIEDMAN, B.; HENDRY, D. The Envisioning Cards: A Toolkit for Catalyzing Humanistic and Technical Imaginations. In: CHI '12 Proceedings of the SIGCHI Conference on Human Factors in Computing Systems, 2012, Austin. Anais... Nova York: ACM, 2012, p. 1145-1148.

FRIEDMAN, B.; KAHN, P. H.; BORNING, A. Value Sensitive Design and Information Systems.

Human-Computer Interaction and

Management Information Systems:

Foundations Advances in Management

Information Systems, v. 5. M.E. Sharpe, NY, 2006, p. 348-372.
Realização:
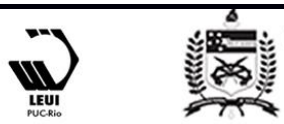


\section{$16^{\circ}$ \\ ERGODESIGN USIHC CINAHPA}

$16^{\circ}$ Ergodesign - Congresso Internacional de Ergonomia e Usabilidade de Interfaces Humano Tecnológica: Produto, Informações Ambientes Construídos e Transporte

$16^{\circ}$ USIHC - Congresso Internacional de Ergonomia e Usabilidade de Interfaces Humano Computador

CINAHPA | 2017 - Congresso Internacional de Ambientes Hipermídia para Aprendizagem.
FROEHLICH, J. E. Sensing and Feedback of Everyday Activities to Promote Environmental Behaviors. Washington, 2011, 381f. Tese (Doutorado em Ciências da Computação) Department of Computer Science and Engineering - University of Washington.

GOTHELF, J. Lean UX: applying lean principles to improve user experience. Sebastopol: O'Reilly, 2013.130p.

HOLMES, T.; BLACKMORE, E.; HAWKINS, R. The Common Cause Handbook. Public Interest Research Centre, UK, 2011. Disponível em $<\mathrm{http}: / /$ publicinterest.org.uk/the-common-causehandbook/> Acesso em: 14 dec. 2015.

KARP, D. G. Values and their effect on proenvironmental behavior. Environment and Behavior, v.28, n.1, p.111-133, 1996.

KNOWLES, B. et al. Patterns of persuasion for sustainability. In: DIS '14 Proceedings of the 2014 conference on Designing interactive systems, 2014, Vancouver. Anais... Nova York: ACM, 2014, p. 1035-1044.

NATHAN, L.P., HENDRY, D., FRIEDMAN, B. Information system design as catalyst: Human action and environmental sustainability.

Interactions, vol.16, Issue 4, 2009, p.6-11.

PADOVANI, S.; SCHLEMMER, A.; SCARIOT, C.A. Usabilidade \& User Experience, Usabilidade Versus User Experience, Usabilidade em User Experience? Uma discussão teórico-metodológica sobre comunalidades e diferenças. In: $12^{\circ}$

Ergodesign - Usihc, 2012, Natal. Anais... Natal: LEUI - LEXUS, 2012, p. 13- 01-13- 10.

PATO-OLIVEIRA, C. M. L.; TAMAYO, A. Os valores como preditores de atitudes e comportamentos: contribuições para um debate. Linhas Críticas, Brasília, v.8, n.14, p.103-117, 2002.

PATO, C. M. L.; TAMAYO, A. A Escala de Comportamento Ecológico: desenvolvimento e validação de um instrumento de medida. Estudos de Psicologia, Campinas, v.11, n.3, p.289-296,
2006.

ROKEACH, M. Crenças, atitudes e valores uma teoria de organização e mudança. Rio de Janeiro: Interciência, 1981

SAFFER, D. Designing for Interaction, Creating Innovative Applications and Device. $2^{\mathrm{a}} \mathrm{ed}$. Edição Kindle. Berkeley: New Riders, 2010.

SCHWARTZ, S. H. An Overview of the Schwartz Theory of Basic Values. Online Readings in Psychology and Culture, v. 2, n.1, 2012.

SCHWARTZ, S. H. Universals in the content and structure of values: Theoretical advances and empirical tests in 20 countries. Em M. P. Zanna (Ed.). Advances in Experimental Social Psychology, vol. 25, 1992, p.1-65.

SHEDROFF, N. Design is the Problem: The Future of Design Must be Sustainable. Brooklyn :Rosenfeld Media, 2009. 319p.

STERN, P. C. Toward a Coherent Theory of Environmentally Significant Behavior. Journal of Social Issues, v.56, n.3, p.407-424, 2000. 